\title{
Are We on the Same Page? Knowledge Boundaries and Transactive Memory System Development in Cross-functional Teams
}

\author{
Julia Kotlarsky ${ }^{1}$, Bart van den Hooff ${ }^{2}$ and Leonie Houtman ${ }^{2}$
}

\begin{abstract}
One of the key challenges that organizations face when trying to integrate knowledge across different functions is the need to overcome knowledge boundaries between team members. In cross-functional teams these boundaries, associated with different knowledge backgrounds of people from various disciplines, create communication problems, necessitating team members to engage in complex cognitive processes when integrating knowledge towards a joint outcome. This research investigates the impact of syntactic, semantic and pragmatic knowledge boundaries on a team's ability to develop a Transactive Memory System (TMS) a collective memory system for knowledge coordination in groups. Results from our survey show that syntactic and pragmatic knowledge boundaries negatively affect TMS development. These findings extend TMS theory beyond the information processing view, which treats knowledge as an object that can be stored and retrieved, with the interpretive and practice-based views of knowledge, which recognize that knowledge (in particular specialized knowledge) is localized, situated and embedded in practice.
\end{abstract}

Keywords: transactive memory system; cross-functional team; syntactic, semantic and pragmatic knowledge boundaries.

\footnotetext{
${ }^{1}$ Aston Business School, Aston University, UK (email: j.kotlarsky@aston.ac.uk)

${ }^{2}$ Vrije University Amsterdam, Netherlands
} 


\section{Are We on the Same Page? Knowledge Boundaries and Transactive Memory System Development in Cross-functional Teams}

Cross-functional or multidisciplinary teams, in which representatives from different knowledge domains work together to accomplish a joint task, face challenges in balancing knowledge differentiation and integration as they work to achieve a joint outcome (Liao, Jimmieson, O’Brien, \& Restubog, 2012; Majchrzak, More, \& Faraj, 2012; Oborn \& Dawson, 2010). Differences in perceptions, practices and representations associated with knowledge specialization create communication problems in cross-functional teams, necessitating team members to engage in complex cognitive processes when integrating knowledge from different domains.

Cognitive processes in teams have been studied in depth through the lens of Transactive Memory System (TMS) theory. A TMS is a collective memory system, consisting of the combination of individual memory systems and communications between individuals, enabling the shared division of cognitive labor to encode, store and retrieve knowledge from different but complementary domains of expertise in collective tasks (Liang, Moreland, \& Argote, 1995; Wegner, 1986; Wegner, 1995; Wegner, Erber, \& Raymond, 1991; Wegner, Guiliano, \& Hertel, 1985). On the one hand, specialization (leading to differentiated knowledge) is considered a key characteristic of TMS; on the other hand, some common knowledge is required to coordinate this differentiated knowledge in order for a TMS to be efficient (Lewis, 2003; Lewis \& Herndon, 2011; Ren \& Argote, 2011). However, while it is argued that the usefulness of a TMS depends on both the shared understanding of "who knows what" and the degree to which knowledge is differentiated (Lewis \& Herndon, 2011 p. 1256), it is not clear what the "right" balance between the two is. As Lewis (2003 p.602) puts it, "What we do not know is how much knowledge must be overlapping, and how 
much specialization is too much". We believe that this inherent tension in TMS theory warrants a closer look at the nature of the knowledge involved. This tension between shared and differentiated knowledge is especially manifested in cross-functional teams, due to the high degree of knowledge differentiation resulting from the differences in knowledge domains in these teams ${ }^{1}$.

In this paper we aim to unravel this tension by linking TMS theory to Carlile's (2002, 2004) theory of Knowledge Boundaries. Carlile distinguishes three knowledge boundaries that can emerge at the boundaries between practices associated with different professional disciplines: (1) syntactic boundaries, resulting from differences in vocabulary and lexicon, (2) semantic boundaries, caused by different interpretations across different practices and (3) pragmatic boundaries, related to differences in interests that question key assumptions inherent to a particular practice. These boundaries create obstacles for communication, and impede knowledge integration between members of cross-functional teams (Carlile, 2004; Liao et al., 2012). Effectiveness of knowledge sharing in such teams to a great extent relies on the existence of a common knowledge that individuals from different professional communities use to share and access each other's domain-specific knowledge (Carlile, 2004).

TMS research has primarily been grounded in the information processing view (Galbraith, 1973; Lawrence \& Lorsch, 1967) which treats knowledge as an object that can be stored and retrieved (Liao et al., 2012). In this view, team members are considered as information processors who encode and store information about "who knows what" in the team (Liao et al., 2012; Wegner, 1986), and use this information to retrieve relevant specialized knowledge in a similar manner to computers "downloading" information from a database, as described by Wegner (1995) using the computer network metaphor. A few recent TMS studies recognized that TMS is not simply a cognitive exercise of processing information, but a social cognitive phenomenon where the context and nature of 
communication influences TMS development in teams (Liao et al., 2012; Ren \& Argote, 2011).

The knowledge boundaries lens applied in this paper integrates the information processing view with approaches that highlight the communicative and socially constructed nature of knowledge, and the extent to which it is situated within or transferrable across particular contexts (Carlile, 2002). These approaches are (1) the interpretive view that emphasizes the importance of achieving shared meaning between actors (Boland \& Tenkasi, 1995; Dougherty, 1992), and (2) the practice-based view that acknowledges how differences in practices (and interests related to these practices) impede knowledge sharing (Brown \& Duguid, 1991; Cook \& Brown, 1999). Thus, adopting the knowledge boundaries perspective, we argue that differences in specialized knowledge in a team can be explained by (combinations of) syntactic, semantic or pragmatic boundaries. Such boundaries impede communication between team members, and since communication is a crucial determinant of TMS development (Hollingshead, 1998; Hollingshead \& Brandon, 2003; Lewis, 2004; Palazzolo, 2005), different knowledge boundaries may have different impacts on the development of a TMS in cross-functional teams. Therefore, we address the following research question: How do syntactic, semantic and pragmatic knowledge boundaries influence the development of a TMS in cross-functional teams?

This paper offers two contributions to the literature. First, our study extends current TMS theory by studying the impact of various origins of knowledge differentiation between team members (i.e., the different types of knowledge boundaries) on communication between team members, and through that, on TMS development. Second, this research extends Knowledge Boundaries theory, as we also hypothesize and empirically test interdependencies between the knowledge boundaries (which are suggested but not tested empirically in the Knowledge Boundaries theory by Carlile). 
The paper is organized as follows. The next section explains TMS theory and discusses the role of differentiated knowledge in this theory. Then, we introduce Knowledge Boundaries theory and discuss how knowledge of team members can be differentiated, distinguishing between syntactic, semantic and pragmatic knowledge boundaries. We develop a set of hypotheses linking these three knowledge boundaries with TMS development, and inter-dependencies between the boundaries. Then, we present the methodology and results of a survey study of cross-functional teams from a large Dutch Healthcare Research Institute. We then discuss our results and conclude the paper with theoretical and practical implications followed by limitations and suggestions for future research.

\section{Literature Review}

\section{Transactive Memory System Theory}

A Transactive Memory System (TMS) is defined as a collective memory system, consisting of the combination of individual memory systems and communications between individuals that enable the shared division of cognitive labor used to encode, store and retrieve knowledge from different but complementary domains of expertise while being engaged in collective tasks (Hollingshead, 2001; Wegner, 1986; Wegner et al., 1985). Group members divide cognitive labor by creating specializations: different individuals specialize in different knowledge domains. They use their individual meta-knowledge about what other group members know to access knowledge of their expert colleagues from other specialist areas to complement their own knowledge when needed.

TMS research originated in the field of psychology, and was first formulated by Wegner and colleagues (Wegner, 1986; Wegner, 1995; Wegner et al., 1991; Wegner et al., 1985) with a focus on close relationships among married couples. It was further extended to dyads and couples beyond those engaged in close relationships by Hollingshead and 
colleagues (Hollingshead, 1998, 2000, 2001; Hollingshead \& Brandon, 2003; Hollingshead \& Fraidin, 2003), and widely used to study knowledge processes in small groups in a workplace (e.g., Gino, Argote, Miron-Spektor, \& Todorova, 2010; Lewis, 2004; Lewis, Belliveau, Herdon, \& Keller, 2007; Liang et al., 1995; Moreland, 1999; Moreland \& Argote, 2003; Moreland, Argote, \& Krishnan, 1996; Moreland \& Myaskovsky, 2000; Palazzolo, 2005; Yuan, Fulk, Monge, \& Contractor, 2010). Several recent studies extended TMS theory to complex and ad-hoc settings such as organizations (e.g., Anand, Manz, \& Glick, 1998; Jackson \& Klobas, 2008; Nevo, Benbasat, \& Wand, 2012) and dispersed or virtual teams that include members from multiple organizations (e.g., Jarvenpaa \& Majchrzak, 2008; Majchrzak, Jarvenpaa, \& Hollingshead, 2007; Majchrzak \& Malhotra, 2004; Oshri, van Fenema, \& Kotlarsky, 2008; Yoo \& Kanawattanachai, 2001). Scholars studying TMS in such settings extended TMS theory beyond small, well defined interacting groups to show that TMS exists at individual, group and organizational levels, and thus in less clearly delineated settings (Jarvenpaa \& Majchrzak, 2008; Moreland \& Argote, 2003).

In TMS theory, the distinction between differentiated and integrated knowledge is a central issue, as the functioning of a TMS is based on a balance between common (integrated) and specialized (differentiated) knowledge (Gupta \& Hollingshead, 2010; Wegner, 1986). Differentiated group knowledge, which is created when group members develop specializations by dividing knowledge responsibilities (Lewis \& Herndon, 2011) enables division of cognitive labor by reducing individual team members' cognitive load. In TMS theory this knowledge is regarded as a collection of "domains of expertise" (Lewis, 2003 p. 588) or the "team knowledge stock" (Ren \& Argote, 2011 p. 196). Complementary to this specialized knowledge is "common knowledge" or "knowledge of who knows what", since "teams do need to share some overlapping knowledge in order to coordinate their actions and perform well" (Lewis, 2003, p. 602). In TMS research the distinction between teams that 
have more (or less) overlapping knowledge was introduced by referring to differentiated or integrated TMS structures. In a differentiated TMS structure, individuals have a different knowledge domain, but know about areas of expertise of other team members. Integrated transactive memory, on the other hand, occurs when individuals have overlapping knowledge, and team members are aware of this overlap (Gupta \& Hollingshead, 2010; Wegner, 1986).

Both differentiated and common knowledge are part of Lewis' conceptualization of TMS, which distinguishes between specialization, coordination, and credibility - manifestations of a TMS. Specialization refers to the degree of differentiation of knowledge possessed by team members; coordination refers to the team's efficiency in knowledge processing while working together; and credibility refers to beliefs team members have about the reliability of other members' knowledge (Ellis, 2006; Lewis, 2003; Liang et al., 1995). These three variables are conceptualized as manifestations or indicators of the extent to which a TMS has developed in a group, and have been widely used to measure TMS development in empirical research (e.g., Jarvenpaa \& Majchrzak, 2008; Lewis, 2004; Liang et al., 1995; Moreland, 1999). Since the aim of our study is to investigate how knowledge boundaries affect TMS development, this is an appropriate conceptualization for our goals.

Jarvenpaa and Majchrzak (2008) who used these same three manifestations of TMS, in their study, explicitly conceptualized a TMS in terms of individuals' mental models of their ego-centered networks. Our conceptualization of TMS in cross-functional teams is in line with Jarvenpaa and Majchrzak's approach, as we focus on the individual team members' perceptions. Members of cross-functional teams typically represent their function (domain) in a number of teams, often being partly involved in more than one team. Therefore (as in the organization where the data for our study was collected), it is often difficult to define a clear team context. Consequently, and in line with past TMS research that was conducted in teams where a clear team context was difficult to establish (such as the ad-hoc collaborations 
between security professionals in Jarvenpaa and Majchrzak's study) we conceptualize TMS development at an individual level, as one's mental model of who knows what in the network and where to allocate or retrieve knowledge at the individual level. Such a conceptualization of TMS as an individual perception was also found in recent TMS studies focusing on individual group members' perceptions without accounting for team level variance (Child \& Shumate, 2007; Su, 2012).

As for factors affecting the development of a TMS in terms of specialization, credibility and coordination, Ren and Argote (2011) identified three categories of variables: attributes of team members (such as demographics, competences and personality traits), characteristics of a team and the task that team is working on (e.g., team familiarity, task and reward interdependency, whether team members were trained together or separately, communication), and organizational characteristics (such as geographical dispersion and stress levels). In this paper, we focus on communication as a determinant of TMS development.

The role of communication in attaining a balance between differentiated and integrated knowledge is especially crucial in TMS development in cross-functional (or multidisciplinary) teams, which are commonly used within and across organizations for novel and innovative projects and initiatives. The few TMS studies that focused on such teams highlighted difficulties in TMS development in teams that involved experts from different professional disciplines (Faraj \& Xiao, 2006), in particular if they belong to different organizations and have never worked together in the past (e.g., Majchrzak et al., 2007). These studies challenged an implicit TMS assumption, embedded in the information processing view, that members are motivated to share knowledge (Lewis \& Herndon, 2011). For example, Jarvenpaa and Majchrzak (2008) argued that when individual experts in a group 
have different interests and motives, they might not share the useful knowledge they posses, and may not be motivated to use information they receive. Furthermore, TMS research conducted in cross-functional teams (Faraj \& Xiao, 2006; Jarvenpaa \& Keating, 2011; Jarvenpaa \& Majchrzak, 2008; Majchrzak et al., 2007) shows that members of such teams have difficulties in communicating with their counterparts, either regarding encoding and storing new knowledge (e.g., if they do not have an accurate awareness of the expertise of other team members) or when attempting to retrieve or access specialized knowledge from other team members (e.g., if team members find it difficult to understand each other or have incongruent goals). Furthermore, it was argued that social aspects, such as cultural differences (e.g., Jarvenpaa \& Keating, 2011) and professional identification (e.g., Liao et al., 2012) influence communication between team members.

Communication is identified as a crucial determinant of TMS development in a wide range of studies (Hollingshead, 1998; Hollingshead \& Brandon, 2003; Kanawattanachai \& Yoo, 2007; Lewis, 2004; Liao et al., 2012; Palazzolo, 2005). Communication is essential in order to learn about what others know, for encoding new knowledge into the group TMS, and for retrieving knowledge from the group's TMS (Hollingshead \& Brandon, 2003). Thus, communication processes play a key role in both the development and use of a group TMS (Hollingshead \& Brandon, 2003; Lewis, 2004). Liao et al. (2012) argue that it is not only the quantity of communication that matters here (i.e., the frequency of interaction), but also the quality of communication (the usefulness and the affective quality of interactions) that influences TMS development.

Our central assumption is that, in multidisciplinary teams, syntactic, semantic and pragmatic knowledge boundaries that emerge between experts from different knowledge domains form impediments to communication between team members. Consequently, these boundaries will negatively influence TMS development in these teams. In the next section, 
Carlile's $(2002,2004)$ conceptualization of knowledge boundaries will be discussed, and related to TMS development in cross-functional teams.

\section{Knowledge Boundaries and TMS Development}

TMS research tends to follow the information processing view and regard knowledge as an object that can be accessed if group members have meta-knowledge about who knows what (Lewis, 2003 p. 588). This view disregards the differences in specialized knowledge of group members, and the origins of such differences. The literature on the interpretive and practicebased views of knowledge, however, does provide insight into where knowledge differentiation comes from. According to this literature, knowledge is not simply an aggregate of information which can be de-coupled from its context, but is inherently tacit and embedded in social and practical contexts (Bourdieu, 1990; Levina \& Vaast, 2005; Orlikowski, 2002). Thus, learning and knowledge processes take place where practices are shared in a rich and meaningful way (Brown \& Duguid, 1998, 2001; Cook \& Brown, 1999). However, where shared practices are absent, boundaries emerge that impede learning and knowledge processes (Levina \& Vaast, 2008).

Where different practices meet, "knowledge boundaries" emerge, which are differences in knowledge that is localized, embedded and invested in different practices. Consequently, such knowledge boundaries are particularly evident in cross-functional teams. On the one hand, teams that bring together members from different knowledge domains and professional backgrounds have a broader range of potential knowledge at their disposal. On the other hand, the diversity in expertise and knowledge backgrounds can also create boundaries that impede knowledge sharing between specialized domains (Mitchell, Parker, \& Giles, 2011). Carlile (2002 p. 442) explicitly relates these boundaries to the balance between knowledge differentiation and integration: 
"It is at these 'knowledge boundaries' that we find the deep problems that specialized knowledge poses to organizations. The irony is that these knowledge boundaries are not only a critical challenge, but also a perpetual necessity because much of what organizations produce has a foundation in the specialization of different kinds of knowledge."

Carlile distinguishes three "progressively complex boundaries" (Carlile, 2004 p. 555), which are rooted in Shannon and Weaver's (1949) fundamental theory of communication: syntactic (differences in lexicon), semantic (differences in interpretations) and pragmatic (differences in interests) boundaries. These boundaries are communication boundaries: they are found at the level of interpersonal interaction - they are not group properties. Whether a boundary exists or not, is very much determined by how individual team members perceive their communication with fellow members. In line with the above, our focus is on individual perceptions of these boundaries. As explained above, our focus is also on individual perceptions of TMS development. Our hypotheses, consequently, concern hypothesized relationships between individual team members' perceptions of knowledge boundaries they encounter in interacting with others in various team contexts on the one hand, and their mental model of team TMS on the other.

Syntactic knowledge boundaries concern differences in terminologies, codes, protocols, routines or other means of expression. Basically, a syntactic boundary emerges as a consequence of differences in vocabulary and ways of articulating the meaning of issues (Carlile, 2002). This boundary is rooted in the information processing view and associated with the mathematical theory of communication (Shannon \& Weaver, 1949). It implies that once a shared syntax is established, information can be processed. Thus, consequences of this boundary can be reduced if a common lexicon is developed and information artifacts, such as 
standards, repositories and specifications, are made available for the parties involved (Kellogg, Orlikowski, \& Yates, 2006).

Syntactic boundaries between team members are likely to negatively influence TMS development since they cause difficulties in recognizing each other's expertise. In other words, communication about who knows what is hampered by a lack of a shared syntax, so that expertise recognition will be less accurate and there will be lack of consensus across team members regarding who knows what. Consequently, team members may not know whom to contact to retrieve relevant knowledge, or to which other team members to allocate incoming information. Therefore, we hypothesize:

H1. A higher syntactic knowledge boundary will negatively influence the development of a TMS in a cross-functional team.

Semantic knowledge boundaries are related to the problem of different interpretations across different practices - differences in sense making, in meanings attached to certain phenomena. Based on their own practices, team members tend to make assumptions that are rooted in their own experiential and situated knowledge. Such assumptions, often made unconsciously based on the core values and beliefs of their "thought world", are not obvious to all team members, and can even contradict others' assumptions, creating difficulties in communication across these thought worlds (Carlile, 2002; Dougherty, 1992). This complicates the creation of a "shared mental model" (Canon-Bowers, Salas, \& Converse, 1993), where team members have common knowledge structures that help them to describe, explain, and predict events in their environment (Mathieu, Heffner, Goodwin, Salas, \& Cannon-Bowers, 2000). As Edmondson and Nembhard (2009 p. 128-9) put it: "Team members have been socialized to abide by their professions' principles, views, and habits, which become taken-for-granted mental models, making transcendence of their own views 
and understanding of others' views a significant challenge". "Translating" knowledge across a semantic boundary requires individuals to understand novel conditions and learn about the sources of these different assumptions (Carlile, 2002; Kellogg et al., 2006; Levina \& Vaast, 2005; Oborn \& Dawson, 2010).

A semantic boundary is also likely to negatively influence TMS development. Where team members' interpretations diverge, this creates challenges for communication and collaboration between team members (Carlile, 2002; Majchrzak et al., 2012). This poses problems for TMS development, because even when team members use common terminology, they may interpret the meaning of the knowledge they retrieve from other actors differently (or knowledge contributions of others to the collective outcome). Thus, misunderstandings are likely to surface, which will also negatively influence the extent to which expertise is retrieved and allocated within a cross-functional team. Therefore, we hypothesize:

H2. A higher semantic knowledge boundary will negatively influence the development of a TMS in a cross-functional team.

Pragmatic knowledge boundaries are related to differences in interests, existing practices, goals and other aspects that have become common sense in particular knowledge domains. Reducing these differences requires the transformation of existing localized knowledge into new knowledge (Carlile, 2004). As Carlile (2002 p. 445) formulates it, the challenge at the pragmatic level "is not just that communication is hard, but that to resolve the negative consequences by the individuals from each function they have to be willing to alter their own knowledge, but also be capable of influencing or transforming the knowledge used by the other function". For knowledge transformation to take place, common interests need to be developed in a shared practice which would provide a common ground for sharing and 
adjusting the knowledge at a boundary (Bechky, 2003; Carlile, 2004). As Swan et al (2007) state, a shared locus of practice creates a common ground for communication and knowledge sharing, allowing for the re-contextualization of local understandings in joint activity.

Since the key characteristic of a cross-functional team is the diversity of specialized expertise brought together to collaborate towards a joint outcome, the pragmatic boundary is likely to constitute a prominent barrier to TMS development in these teams. Individuals from different domains bring diverse interests to the teamwork; they are guided by different goals, constraints and performance indicators of their professional area. As team members face divergent interests, they face difficulties creating a common ground. Thus, creating a shared locus of practice is problematic, which means that members' motivation to communicate to better understand other team members' knowledge and find acceptable solutions is likely to decrease (Barrett \& Oborn, 2010; Brown \& Duguid, 2001; Jarvenpaa \& Majchrzak, 2008). Furthermore, in multidisciplinary teams communications between members from different professional domains will be affected by salience of their professional identification associated with (i) threat to lose their professional identity, (ii) "we versus them" attitudes and (iii) perception of status (un)equality among professional subgroups (Liao et al., 2012). Hence, both the quantity and quality of communication will be negatively affected, which will have negative consequences for TMS development. Therefore, we hypothesize:

H3. A higher pragmatic knowledge boundary will negatively influence the development of a TMS in a cross-functional team.

\section{Interrelatedness of Knowledge Boundaries}

The nature of the syntactic, semantic and pragmatic boundaries as described by Carlile (2002, 2004) suggests that these boundaries are interrelated. Following the practice-based perspective on knowledge and Carlile's own "pragmatic view", the pragmatic boundary is the 
fundamental boundary causing differences in knowledge. Since knowledge and knowing cannot be separated from an individual's engagement in their practice (Cook \& Brown, 1999), individuals are immersed in thought worlds of their practice (Bechky, 2003), which strongly determines their interpretations and understandings of relevant issues, through joint sense-making (Wenger, 1998) within their practice. Achieving common understanding between individuals from different practices through joint sense-making across practices requires the motivation of participants and their willingness to listen, explain, and be open to alternative interpretations, a process referred to as perspective taking (Boland \& Tenkasi, 1995). However, this is less likely to happen if these individuals face a pragmatic knowledge boundary (i.e., the need to question the relevance of their own knowledge and change their goals), in addition to discussing and altering interpretations. Therefore, we argue that where a pragmatic boundary exists, a semantic boundary is likely to emerge as well (as summarized in Hypothesis 4a below).

Likewise, engagement in joint sense-making across practices, when individuals need to find a way to accommodate different interests, procedures and values they bring to the table, is likely to generate syntactic difficulties for communication. Such difficulties are rooted in thought worlds associated with different practices that include context- and practice-related terminology and jargon. Therefore individuals from different domains often use different words and concepts to talk about the same object (Bechky, 2003), or attach different meanings to the same words, or use specialized terms that are known only to specialists from their knowledge domain, thus frustrating perspective taking between disciplines (Boland \& Tenkasi, 1995). This leads us to expect that the existence of a pragmatic boundary will also give rise to a syntactic boundary (as summarized in Hypothesis $4 \mathrm{~b}$ below).

Finally, a syntactic boundary is likely to give rise to a semantic boundary as well, as summarized in Hypothesis 4c below. As Bechky (2003) argues, differences in the use of 
words and concepts (i.e., a syntactic knowledge boundary) are likely to lead to differences in the understanding of the problems faced within different practices. Also, as Carlile (2004) notes, where a common lexicon is not present, it will be impossible to create common meaning - in other words, where agreement on words and concepts is not present, a shared mental model is not likely to arise. Together, this leads us to hypothesize the following interrelatedness between the three types of knowledge boundaries:

H4. The knowledge boundaries will be interrelated, such that the pragmatic boundary will increase the (H4a) semantic and (H4b) syntactic boundaries; and (H4c) the syntactic boundary will increase the semantic boundary.

Our theoretical model depicted in Figure 1 illustrates the hypothesized relationship between knowledge boundaries and TMS in cross-functional teams.

\section{INSERT FIGURE 1 ABOUT HERE}

\section{Research Design and Methods}

To test the theoretical model and answer the research question we conducted a survey study in a large Dutch Healthcare Research Institute (from here on referred to as HRI). The survey was preceded by interviews with six individuals from different functions within the organization in order to gain a thorough understanding of the functioning of and the cognitive processes within cross-functional teams, knowledge sharing and possible difficulties inhibiting knowledge sharing (see information about interviewees in Appendix A). Information obtained from these interviews was used to tailor the survey instrument. The focus of the survey was on knowledge sharing, collaboration and knowledge boundaries within cross-functional project teams. 
HRI is structured by functions (departments), and employees typically share their time between work associated with their specific function, and (one or more) projects that involve individuals from several functions. Typically HRI employees belong to project teams that cross the boundaries between functional departments, as their work revolves around multidisciplinary topics with a high level of complexity that requires expertise from different fields. As the tasks of the organization increasingly demanded an integrated approach to solving problems, management saw this as a potential difficulty and thus wanted to obtain insights into how sharing and integration of knowledge between different functional departments could be stimulated. A request to complete an online questionnaire was sent out to 533 employees. Ultimately, 174 respondents (33\%) completed the survey. Individuals from 16 different functional departments (i.e., specialized research centers or laboratories) participated in the survey. Nine of these 16 departments focus on research concerning various environmental and safety issues, and the other seven departments are involved in research concerning various healthcare issues.

An example of a multi-disciplinary project that involves individuals from various departments is one that focuses on the health impact of modern-day airports, which involves several experts that are specialized in different areas working together on issues related to environmental safety, toxicology and air quality. All organizational members work in crossfunctional project teams, varying in size between two to 30 project members, and in project duration between half a day and up to four years. Through the interviews we were able to get an idea of the knowledge boundaries that members of cross-functional teams at HRI had experienced. Table 1 below includes the most representative quotes from the interviews illustrating (1) all three types of knowledge boundaries, (2) the importance of a TMS and (3) interrelatedness between knowledge boundaries. 


\section{INSERT TABLE 1 ABOUT HERE}

Measures. In the survey, all items were measured using a 1-5 point (strongly disagree - strongly agree) Likert-type scale. Respondents were asked to give their opinion on these items based on the most important project they were currently working on, or had recently been working on - i.e., the project on which they spent most of their time. The opening sentence in the questionnaire asked respondent to focus on the current, or most recently completed, cross-functional project (s)he was involved in. Since project teams often had a strongly fluctuating composition and involved many external parties (from universities, companies, other research institutes), it was not possible to clearly define beforehand the team context for the statements about TMS and knowledge boundaries. In other words, the responses concerned individual respondents' perceptions of the collaboration in their most recent project team, and these could not be aggregated to the project team level (since the "project team" as such was very difficult to define taking into account that some employees were involved in more than one cross-functional team, and some members of project teams were not included in the survey since they were external parties). Therefore, as stated earlier, we followed an approach adopted from recent studies in settings where a clear team context was absent, and measured individual perceptions of knowledge boundaries and TMS. This approach is consistent with recent research that studied team level phenomena on the individual level in settings where a clear team context was absent, such as Jarvenpaa and Majchrzak's (2008) study concerning TMS development in ad-hoc collaborations between security professionals, or De Vries, Van den Hooff and De Ridder's (2006) study in which team communication styles were measured in a similar way.

Lewis' (2003) scale based on specialization, credibility and coordination was used to measure TMS in the cross-functional teams within HRI. This scale was used to measure the 
individual respondents' perceptions of the level of specialization (e.g. "Each team member has specialized knowledge of some aspect of our project"), credibility (e.g. "I am confident relying on the information that other team members brought to the discussion") and coordination (e.g. "Our team works together in a well-coordinated fashion"). This approach is in line with Jarvenpaa and Majchrzak (2008) who adopted Lewis' (2003) scale to measure individual perceptions of specialization, credibility and coordination, and combined these into a measure for TMS development. The scales for the three knowledge boundaries were newly designed and validated, in line with procedures adopted in past research that used new scales (e.g., Jarvenpaa \& Majchrzak, 2008). As we did not find any quantitative measures for knowledge boundaries in the existing literature, we constructed survey questions for each of the three knowledge boundaries derived from the conceptual description of knowledge boundaries based on Carlile (2002) and other relevant sources (discussed in the "Knowledge boundaries and TMS development" section). These items were pilot tested in a survey study $(\mathrm{N}=150)$ we conducted in cross-functional teams in a large municipal organization (Kotlarsky, Van den Hooff, \& Huysman, 2009). Based on this pilot study, some items of these scales were slightly adapted or reworded for the current study. Three experts with considerable experience in knowledge management research reviewed these adapted items for clarity and appropriateness to the construct. A complete overview of the items used to measure each construct can be found in Table 2 .

SmartPLS 2.0 software was used to analyze both the psychometric properties of these measures (measurement model) and the structural relations between them (structural model), following recommended two-stage analytical procedures (Hair, Black, Babin, Anderson, \& Tatham, 2006). Because all our variables were collected concurrently (using the same survey among the same sample of respondents), common method variance is a potential threat to the internal validity of our results. Based on Podsakoff and Organ (1986), we assessed common 
method variance by using Harman's one factor test to check for a single factor explaining a majority of the variance. We conducted a principal component analysis containing all manifest items. Six factors explained $65 \%$ of the total variance, with the first factor explaining $34 \%$, so no single factor explained a majority of the variance in our constructs. Based on these results, we can conclude that common method variance is not an issue that threatens the validity of our results.

Measurement model. Confirmatory factor analysis (CFA) was used to assess the validity and reliability of the measures. TMS is considered to be a second order construct, consisting of the first order constructs specialization, credibility and coordination. As Lewis and Herndon (2011) state, these concepts are distinct manifest variables, but "the three manifest variables cannot be meaningfully analyzed or interpreted in separation. Considered separately, the specialization, credibility and coordination variable do not imply that a TMS exists" (p.4). Therefore, a first CFA was performed to test the psychometric qualities of the scales measuring the three concepts. In this model, the three concepts are latent variables, measured by their respective indicators (i.e, survey items). The results of this first analysis are shown in Table 2. Due to insufficient factor loadings, four of the original 15 items of this scale (as developed by Lewis, 2003) were discarded (two for specialization, one for credibility, and one for coordination), leaving 11 items for further analysis.

\section{INSERT TABLE 2 ABOUT HERE}

Table 2 shows the latent variables, the indicators measuring these scales, the factor loadings of these items, as well as the CR and AVE values. To assess convergent validity of the measurements used, the average variance extracted (AVE) for each of the theoretical constructs was examined (Fornell \& Larcker, 1981). The AVE values of all theoretical 
constructs exceeded the generally recognized 0.50 , indicating that the majority of the variance in the original items is accounted for by the construct. In addition, within every latent variable, every indicator was checked to have statistically significant factor loadings exceeding 0.50 (Hair et al., 2006). In other words, convergent validity was met. Furthermore, the $\mathrm{CR}$ values were all above 0.70 which indicates sufficient reliability.

Discriminant validity was confirmed by comparing the within-construct factor loadings with across-construct loadings. Since all within-construct item loadings were high (all exceeding 0.50, and except for two even exceeding 0.70), and clearly higher than the cross-loadings, discriminant validity could be assumed. Moreover, the square roots of the AVE values of each of the theoretical constructs were compared with the correlations among the theoretical constructs. For discriminant validity, a construct should share more variance with its measures than with other constructs in the model (Chin, 1998), a criterion which was met by these scales: all AVE square roots exceeded the values of the correlations among the constructs in the corresponding rows and columns, as shown in Table 3. As such, discriminant validity was confirmed (Fornell \& Larcker, 1981).

\section{INSERT TABLE 3 ABOUT HERE}

Then, in line with the two-step approach that is common in analyses involving higher order constructs (Agarwal \& Karahanna, 2000), the latent variable scores (i.e., the mean scores for specialization, credibility and coordination) were included in a subsequent CFA in which TMS is included as a latent variable, consisting of the three indicators specialization, credibility and coordination, together with the three knowledge boundaries as latent variables measured by their respective indicators (i.e., survey items). Initially, each of the three knowledge boundary scales consisted of four items. In the process of analysis, however, one 
item for the syntactic boundary and one item for the pragmatic boundary were found to lack in face validity, and consequently these items were discarded. The results of this analysis are shown in Table 4.

\section{INSERT TABLE 4 ABOUT HERE}

Again, the results shown in Table 4 confirm the convergent validity of the measurements, with AVE values exceeding 0.50 for all constructs, factor loadings all higher than 0.50 and CR values above 0.70 . Also, all within-construct loadings were clearly higher than the crossloadings, and the AVE square roots exceeded the correlations between the constructs, as shown in Table 5.

\section{INSERT TABLE 5 ABOUT HERE}

Together, the results presented in Tables 2 through 5 confirm the reliability and validity of our measures, allowing the use of these measures for hypotheses testing.

\section{Results: Hypotheses Testing}

We tested our research hypotheses by examining (a) the size and significance of structural paths in the PLS analysis output and (b) the proportion of variance explained in each of the three dependent variables. Path significance was assessed using bootstrapping techniques, a nonparametric approach for estimating the precision of paths. We controlled for tenure, which has also been found to influence TMS development (Moreland, 1999) but which had no significant influence here. The results of the testing of the structural model are shown in Figure 2 below.

INSERT FIGURE 2 ABOUT HERE 
First, the model proves to have sufficient explanatory power, as it explains $41 \%$ of the variance in TMS development, $18 \%$ of the variance in the syntactic boundary, and $43 \%$ of the variance in the semantic boundary. Furthermore, the model provides support for most of our hypotheses. In line with Hypotheses 1 and 3, we find that both a pragmatic and a syntactic knowledge boundary negatively affect TMS development. Furthermore, in line with Hypotheses $4 \mathrm{a}, 4 \mathrm{~b}$ and $4 \mathrm{c}$, the results show that the boundaries influence each other as expected: a pragmatic knowledge boundary leads to higher semantic and syntactic boundaries, and a syntactic boundary increases a semantic boundary as well. The only hypothesis that has to be rejected on the basis of our results is Hypothesis 2, as the influence of the semantic boundary on TMS development failed to reach significance.

\section{Discussion}

Our study investigated the influence of knowledge boundaries on the development of a Transactive Memory System in cross-functional teams. In line with our expectations, we found that syntactic and pragmatic knowledge boundaries negatively affect TMS development. Furthermore, our results show interdependencies between knowledge boundaries, in particular that a pragmatic knowledge boundary leads to higher semantic and syntactic boundaries, and a syntactic boundary increases a semantic boundary. Contrary to our expectations, no influence of a semantic boundary on TMS development in crossfunctional teams was found. We discuss the implications of these findings below.

The main theoretical contribution of our study lies in extending TMS theory beyond the information processing view, which tends to create an "objectivist" view of knowledge (Hislop, 2009), conceptualizing team members' domain expertise as an object that can be retrieved when needed. Building on the few studies of TMS in cross-functional or 
multidisciplinary teams that identified the need for extending TMS to explain knowledge coordination in such teams (e.g., Faraj \& Xiao, 2006; Jarvenpaa \& Majchrzak, 2008; Liao et al., 2012; Majchrzak et al., 2007), we argued that TMS theory should acknowledge that knowledge (in particular specialized knowledge) is localized, situated and embedded in practice. These knowledge properties are especially evident in cross-functional teams that are characterized by a high degree of knowledge differentiation. Through the lens of the Knowledge Boundaries theory (integrating the information processing view with the interpretive and practice-based views of knowledge) we argued that difficulties in communication between members of cross-functional teams can have different origins: syntactic, semantic or pragmatic boundaries. Acknowledging these different origins of impediments to communication and TMS development may help teams to design communication patterns that aim to resolve the specific boundary team members are facing. For example, aiming to establish common vocabulary between team members that face conflicting goals is not going to help, as tension associated with incongruent goals will remain. Instead, members should engage in dialogic practices and knowledge dissemination protocols (Jarvenpaa \& Majchrzak, 2008) and develop prototypes (Carlile, 2004) that would help to achieve agreement which, in turn, will reduce the pragmatic knowledge boundary.

Moreover, our findings extend understanding of one of the main TMS components, the "team knowledge stock", the knowledge that team members possess in their combined individual memories (Ren \& Argote, 2011; Wegner et al., 1985). Based on our findings we "unpack" this TMS component and argue that a "team knowledge stock" is not a stable collection of shared knowledge objects which can be retrieved when necessary, but a dynamic, constantly changing system of practice-specific knowledge that can be both differentiated and integrated. Retrieving knowledge from this system is often far from easy, especially in cross-functional teams, as boundaries emerge between the various practices (or 
knowledge domains) that are brought together in these teams to work on a common task. This richer and more complex view of a team's collective knowledge is an important contribution, and it would be valuable for future TMS research to incorporate such a conceptualization of "team knowledge stock" in studies of the development and functioning of TMS in crossfunctional teams.

The social, dynamic and interactive nature of knowledge that can be derived from the interpretive and practice-based views also further emphasizes the importance of communication as a determinant of TMS development. Rich and meaningful interactions are required for shared practices (and thus, shared knowledge) to emerge (Hislop, 2009). Thus, our findings provide support for Liao et al's (2012) idea that communication quality is at least as important for TMS development as communication quantity. Communication quality concerns the usefulness (for practice) and affective aspects of interactions (Liao et al., 2012), and the syntactic, semantic and pragmatic boundary will each have their own specific influence on this quality, as outlined above.

Furthermore, we contribute to the literature on knowledge boundaries by exploring the interrelatedness of these boundaries. This interrelatedness has not been explicitly addressed in previous research, and identifying the pragmatic boundary as the fundamental boundary causing differences in knowledge is in line with the practice-based perspective on knowledge (Cook \& Brown, 1999; Hislop, 2009; Orlikowski, 2002). Together with the richer conceptualization of a team's collective knowledge, this can be helpful in shifting the lens of TMS research to a more interpretive and practice-based one. Bridging knowledge boundaries within cross-functional teams does not start with members from different domains understanding each other's language or meaning systems, but with reconciling differences in practices and interests. Defining a collective endeavor, a common goal and interest, and using boundary objects which are jointly used and transformed (Barrett \& Oborn, 2010; Carlile, 
2002; Gasson, 2006; Kellogg et al., 2006; Levina \& Vaast, 2005) will aid in knowledge transformation, which in turn will provide a ground for developing a shared terminology and reconciling different meaning systems.

Finally, the fact that the semantic boundary was not found to significantly affect TMS development can have implications for the conceptualization of TMS in terms of specialization, credibility, and coordination. Although Lewis and Herndon (2011) are explicit in that "the three manifest variables cannot be meaningfully analyzed or interpreted in separation" (p. 4), Ren and Argote (2011, p. 217) actually state that the separate investigation of specialization and coordination "will advance our understanding of transactive memory systems". Since our central assumption is that the tension between differentiation (i.e., specialization) and integration (coordination) is especially manifest in cross-functional teams, we thought it was legitimate to investigate the separate effects of the knowledge boundaries on specialization, credibility and coordination ${ }^{2}$ in an effort to explain the lack of a relationship between the semantic boundary and TMS development. An additional model was run in PLS, in which the three boundaries were each related to specialization, coordination and credibility. The semantic boundary was found to positively influence specialization $(0.229, \mathrm{p}<.05)$, whereas it negatively influenced coordination $(-0.190, \mathrm{p}<.05)$ and credibility (yet not significantly). Consequently, we subscribe to Ren and Argote's (2011) recommendation that future studies indeed not only report on TMS as a construct, but also the value of the different dimensions and their intercorrelations. Particularly in cross-functional teams, where the tension between differentiated and integrated knowledge is especially manifest, integrating specialization and coordination into one measure seems problematic. The fact that the semantic boundary is positively related to specialization, yet negatively to coordination, means that a lack of shared meaning has dual effects on the development of a TMS in cross-functional teams. This emphasizes the fact that there is indeed a clear tension 
between differentiation and integration in cross-functional teams, a tension which deserves to be further explored in future research.

\section{Limitations and Future Research}

Our results are based on one survey conducted in one organization which, by definition, limits the generalizability of our findings. However, given that our research aimed to extend TMS theory by linking it to Knowledge Boundaries theory, our results are a first step in establishing this link which should be investigated in depth in future research. One way forward would be to conduct a similar survey in multiple organizations. From a generalizability perspective, including more organizations in the survey will provide more external validity and reliability to our results. Furthermore, building on our results, the next step in understanding the impact of the various origins of knowledge differentiation between team members (i.e., the different types of knowledge boundaries) on TMS could be to investigate relationships between specific knowledge boundaries and TMS errors, distinguishing between accuracy, sharedness and validation types of errors (Hollingshead, Brandon, Yoon, \& Gupta, 2011).

Next, it is important to mention that while our research included some interviews to help us to better understand the context in which cross-functional teams operate, and get a sense of whether and how team members experience syntactic, semantic and pragmatic knowledge boundaries, overall our use of interviews was limited. Taking into account that knowledge boundaries introduce a practice-based view of knowledge to the TMS theory, we believe that, in line with the practice perspective, further investigation of the relationship between knowledge boundaries and TMS, and of the tension between differentiation and integration in cross-functional teams, calls for richer qualitative data, with more reliance on 
interviews, observations of team meetings and access to team documents and records of communications between team members.

Finally, it should be acknowledged that the relationship between knowledge boundaries and TMS development could be reciprocal. For example, a team with a welldeveloped TMS may experience less communication problems associated with knowledge boundaries. Here we believe that when a new cross-functional team is formed, team members will face knowledge boundaries rooted in their thought worlds and domains of practices. These boundaries will create obstacles for communications, thus inhibiting TMS development. However, over time as the cross-functional team will overcome (some) knowledge boundaries and develop their TMS, they will establish a joint vocabulary, renegotiate their goals and develop expectations of "who acts what" (Jarvenpaa \& Majchrzak, 2008) which, in turn, will reduce knowledge boundaries in the team. Since our research design does not allow us to rule out a possibility of reciprocal relationship, we would recommend to investigate this in future research by conducting longitudinal research, measuring both TMS development and knowledge boundaries at multiple points in time to analyze how the two influence each other. 


\section{References}

Agarwal, R., \& Karahanna, E. (2000). Time Flies when you are Having Fun: Cognitive Absorption and Beliefs about Information Technology Usage. MIS Quarterly, 24(4), 665-694.

Anand, V., Manz, C. C., \& Glick, W. H. (1998). An Organizational Memory Approach to Information Management. Academy of Management Review, 23(4), 796-809.

Barrett, M., \& Oborn, E. (2010). Boundary object use in cross-cultural software development teams. Human Relations, 63(8), 1199-1221.

Bechky, B. A. (2003). Sharing Meaning Across Occupational Communities: The Transformation of Understanding on a Production Floor. Organization Science, 14(3), 312-330.

Boland, R. J., \& Tenkasi, R. V. (1995). Perspective making and perspective taking in communities of knowing. Organization Science, 6(4), 350-372.

Bourdieu, P. (1990). The Logic of Practice. Cambridge, UK: Polity Press.

Brown, J. S., \& Duguid, P. (1991). Organizational learning and communities of practice: Toward a unified view of working, learning, and innovation. Organization Science, 2(1), 40-57.

Brown, J. S., \& Duguid, P. (1998). Organizing Knowledge. California Management Review, 40(3), 90-111.

Brown, J. S., \& Duguid, P. (2001). Knowledge and organization: A social-practice perspective. Organization Science, 12(2), 198-213.

Canon-Bowers, J. A., Salas, E., \& Converse, S. (1993). Shared mental models in expert team decision making. In N. J. Castellan (Ed.), Current issues in individual and group decision making (pp. 221-247). Hillsdale, NJ: Lawrence Erlbaum Associates. 
Carlile, P. (2002). A Pragmatic View of Knowledge and Boundaries: Boundary Objects in New Product Development. Organization Science, 13(4), 442-455.

Carlile, P. (2004). Transferring, Translating and Transforming: An Integrative Framework for Managing Knowledge across Boundaries. Organization Science, 15(5), 555-568.

Child, J. T., \& Shumate, M. (2007). The impact of communal knowledge repositories and people-based knowledge management on perceptions of team effectiveness. Management Communication Quarterly, 21(1), 29-54.

Chin, W. W. (1998). The partial least squares approach to structural equation modeling. In G. A. Marcoulides (Ed.), Modern Methods for Business Research (pp. 295-336). Mahwah, NJ: Lawrence Erlbaum Associates Inc.

Cook, S., \& Brown, J. S. (1999). Bridging Epistemologies: The Generative Dance Between Organizational Knowledge and Organization Knowing. Organization Science, 10(4), $381-400$.

De Vries, R. E., Van den Hooff, B. J., \& De Ridder, J. A. (2006). Explaining knowledge sharing: The role of team communication styles, job satisfaction, and performance beliefs. Communication Research, 33(2), 115-135.

Dougherty, D. (1992). Interpretive barriers to successful product innovation in large firms. . Organization Science, 3(2), 179-202.

Edmondson, A. C., \& Nembhard, I. M. (2009). Product development and learning in project teams: The challenges are the benefits. Journal of Product Innovation Management Communication Quarterly, 26(2), 123-138.

Ellis, A. P. J. (2006). System breakdown: The role of mental models and transactive memory in the relationship between acute stress and team performance. Academy of Management Journal, 49(3), 576-589. 
Faraj, S., \& Xiao, Y. (2006). Coordination in Fast-Response Organizations. Management Science, 52(8), 1155-1169.

Fornell, C., \& Larcker, D. F. (1981). Evaluating structural equation models with unobservable variables and measurement error. Journal of Marketing Research, 18(1), $39-50$.

Galbraith, J. R. (1973). Designing complex organizations. Reading, Massachusetts: AddisonWesley.

Gasson, S. (2006). A genealogical study of boundary-spanning. European Journal of Information Systems, 15(1), 26-41.

Gino, F., Argote, L., Miron-Spektor, E., \& Todorova, G. (2010). First, get your feet wet: The effects of learning from direct and indirect experience on team creativity. Organizational Behavior and Human Decision Processes, 111(2), 102-115.

Gupta, N., \& Hollingshead, A. B. (2010). Differentiated Versus Integrated Transactive Memory Effectiveness: It Depends on the Task. Group Dynamics: Theory, Research, and Practice, 14(4), 384-398.

Hair, J. F., Black, W. C., Babin, B. J., Anderson, R. E., \& Tatham, R. L. (2006). Multivariate Data Analysis (6th ed.). Upper Saddle River, N.J: Pearson Education Inc.

Hislop, D. (2009). Knowledge Management in Organizations Oxford, UK: Oxford University Press.

Hollingshead, A. B. (1998). Communication, learning, and retrieval in transactive memory systems. Journal of Experimental Social Psychology, 34(5), 423-442.

Hollingshead, A. B. (2000). Perceptions of expertise and transactive memory in work relationships. Group Processes and Intergroup Relations, 3(3), 257 - 267. 
Hollingshead, A. B. (2001). Cognitive Interdependence and Convergent Expectations in Transactive Memory. Journal of Personality and Social Psychology, 81(6), 10801089.

Hollingshead, A. B., \& Brandon, D. P. (2003). Potential Benefits of Communication in Transactive Memory Systems. Human Communication Research, 29(4), 607-615.

Hollingshead, A. B., Brandon, D. P., Yoon, K., \& Gupta, N. (2011). Communication and knowledge-sharing errors in groups: A transactive memory perspective. In H. E. Canary \& R. D. McPhee (Eds.), Communication and Organizational Knowledge: Contemporary Issues for Theory and Practice (pp. 133-150). New York: Routledge.

Hollingshead, A. B., \& Fraidin, S. N. (2003). Gender stereotypes and assumptions about expertise in transactive memory Journal of Experimental Social Psychology 39(4), $355-363$.

Jackson, P., \& Klobas, J. (2008). Transactive memory systems in organizations: Implications for knowledge directories Decision Support Systems, 44(2), 409-424.

Jarvenpaa, S. L., \& Keating, E. (2011). Hallowed Grounds: The role of cultural values, practices, and institutions in TMS in an offshored complex engineering services project. . IEEE Transactions on Engineering Management, 58(4), 786-798.

Jarvenpaa, S. L., \& Majchrzak, A. (2008). Knowledge collaboration among professionals protecting national security: Role of transactive memories in ego-centered knowledge networks. Organization Science, 19(2), 260-276.

Kanawattanachai, P., \& Yoo, Y. (2007). The impact of knowledge coordination on virtual team performance over time. MIS Quarterly, 31(4), 783-808.

Kellogg, K. C., Orlikowski, W. J., \& Yates, J. (2006). Life in the Trading Zone: Structuring Coordination Across Boundaries in Postbureaucratic Organizations. Organization Science, 17(1), 22-44. 
Kotlarsky, J., Van den Hooff, B., \& Huysman, M. H. (2009). Bridging Knowledge Boundaries in Cross-Functional Groups: The Role of a Transactive Memory System. Proceedings of the 30th International Conference of Information Systems (ICIS), Phoenix, Arizona, USA.

Lawrence, P., \& Lorsch, J. (1967). Organizations and Environments: Managing Differentiation and Interation. Cambridge, MA: Harvard Business School Press.

Levina, N., \& Vaast, E. (2005). The Emergence of Boundary Spanning Competence in Practice: Implications for Implementation and Use of Information Systems. MIS Quarterly, 29(2), 335-363.

Levina, N., \& Vaast, E. (2008). Innovating Or Doing As Told? Status Differences And Overlapping Boundaries In Offshore Collaboration. MIS Quarterly, 32(2), 307-332.

Lewis, K. (2003). Measuring transactive memory systems in the field: Scale development and validation. Journal of Applied Psychology, 88(4), 587-604.

Lewis, K. (2004). Knowledge and performance in knowledge-worker teams: A longitudinal study of transactive memory systems. Management Science, 50(11), 1519-1533.

Lewis, K., Belliveau, M., Herdon, B., \& Keller, J. (2007). Group cognition, membership change, and performance: Investigating the benefits and detriments of collective knowledge. Organizational Behavior and Human Decision Processes, 103(2), 159 178.

Lewis, K., \& Herndon, B. (2011). Transactive Memory Systems: Current Issues and Future Research Directions. Organization Science, 22(5), 1254-1265. doi: 10.1287/orsc. 1110.0647

Liang, D. W., Moreland, R., \& Argote, L. (1995). Group versus individual training and group performance: The mediating role of transactive memory. Personality and Social Psychology Bulletin, 21, 384-393. 
Liao, J., Jimmieson, N. L., O’Brien, A. T., \& Restubog, S. L. D. (2012). Developing Transactive Memory Systems Theoretical Contributions From a Social Identity Perspective. Group \& Organization Management, 37(2), 204-240

Majchrzak, A., Jarvenpaa, S. L., \& Hollingshead, A. B. (2007). Coordinating Expertise Among Emergent Groups Responding to Disasters Organization Science, 18(1), 147161

Majchrzak, A., \& Malhotra, A. (2004). Virtual Workspace Technology Use and KnowledgeSharing Effectiveness in Distributed Teams: The Influence of a Team's Transactive Memory. Knowledge Management Knowledge Base Retrieved from http://knowledgemanagement.ittoolbox.com/documents/document.asp?i=3164

Majchrzak, A., More, P. H. B., \& Faraj, S. (2012). Transcending Knowledge Differences in Cross-Functional Teams. Organization Science, 23(4), 951-970. doi: 10.1287/orsc. 1110.0677

Mathieu, J. E., Heffner, T. S., Goodwin, G. F., Salas, E., \& Cannon-Bowers, J. A. (2000). The influence of shared mental models on team process and performance. Journal of Applied Psychology, 85(2), 273- 283.

Mitchell, R. J., Parker, V., \& Giles, M. (2011). When do interprofessional teams succeed? Investigating the moderating roles of team and professional identity in interprofessional effectiveness. Human Relations, 64(10), 1321-1343.

Moreland, R. L. (1999). Transactive Memory: Learning Who Knows What in Work Groups and Organizations. In L. Thompson, D. Messick \& J. Levine (Eds.), Shared Cognition in Organizations: The Management of Knowledge (pp. 3-31). Mahwah, NJ: Lawrence Erlbaum. 
Moreland, R. L., \& Argote, L. (2003). Transactive memory in dynamic organizations. In R. Peterson \& E. Mannix (Eds.), Leading and managing people in the dynamic organization (pp. 135-162). Mahwah, NJ: Erlbaum.

Moreland, R. L., Argote, L., \& Krishnan, T. (1996). Social shared cognition at work: Transactive memory and group performance. In J. L. Nye \& A. M. Brower (Eds.), What's So Social About Social Cognition? Social Cognition Research in Small Groups (pp. 57 - 84). Thousand Oaks, CA: Sage.

Moreland, R. L., \& Myaskovsky, L. (2000). Exploring the performance benefits of groups training: transactive memory or improved communication? Organizational Behavior and Human Decision Processes, 82(1), 117-133.

Nevo, D., Benbasat, I., \& Wand, Y. (2012). Understanding Technology Support for Organizational Transactive Memory: Requirements, Application, and Customization. Journal of Management Information Systems, 28(4), 69-98.

Oborn, E., \& Dawson, S. (2010). Knowledge and practice in multidisciplinary teams: Struggle, accommodation and privilege. Human Relations, 63(12), 1835-1857.

Orlikowski, W. J. (2002). Knowing in Practice: Enacting a Collective Capability in Distributed Organizing. Organization Science, 13(3), 249-273.

Oshri, I., van Fenema, P. C., \& Kotlarsky, J. (2008). Knowledge Transfer in Globally Distributed Teams: The Role of Transactive Memory. Information Systems Journal, 18(6), 593-616.

Palazzolo, E. T. (2005). Organizing for Information Retrieval in Transactive Memory Systems. Communication Research, 32(6), 726-761.

Podsakoff, P. M., \& Organ, D. W. (1986). Self-reports in organizational research: Problems and prospects. Journal of Management, 12(4), 531-544. 
Ren, Y., \& Argote, L. (2011). Transactive Memory Systems 1985-2010: An Integrative Framework of Key Dimensions, Antecedents, and Consequences. The Academy of Management Annals, 5(1), 189-229.

Shannon, C., \& Weaver, W. (1949). The Mathematical Theory of Communication. Illinois: University of Illinois Press.

$\mathrm{Su}, \mathrm{C}$. (2012). Who knows what in the group? The effects of communication network centralities, use of digital knowledge repositories, and work remoteness on organizational members' accuracy of expertise recognition. Communication Research, $39(5), 614-640$

Swan, J., Bresnen, M., Newell, S., \& Robertson, M. (2007). The object of knowledge: The role of objects in biomedical innovation. Human Relations, 60(12), 1809-1837.

Wegner, D. M. (1986). Transactive Memory: A Contemporary Analysis of the Group Mind. In G. Mullen \& G. Goethals (Eds.), Theories of Group Behavior. New York: Springer Verlag.

Wegner, D. M. (1995). A Computer Network Model of Human Transactive Memory. Social Cognition, 13, 319-339.

Wegner, D. M., Erber, R., \& Raymond, P. (1991). Transactive memory in close relationships. Journal of Personality and Social Psychology, 61(6), 923-929.

Wegner, D. M., Guiliano, T., \& Hertel, P. T. (1985). Cognitive interdependence in close relationships. In W. J. Ickes (Ed.), Compatible and incompatible relationships (pp. 253-276). New York: Springer-Verlang.

Wenger, E. (1998). Communities of Practice; Learning, Meaning and Identity. Cambridge: Cambridge University Press. 
Yoo, Y., \& Kanawattanachai, P. (2001). Developments of Transactive Memory Systems and Collective Mind in Virtual Teams. International Journal of Organizational Analysis, $9(2), 187-208$.

Yuan, Y. C., Fulk, J., Monge, P. R., \& Contractor, N. S. (2010). Expertise Directory Development, Shared Task Interdependence, and Strength of Communication Network Ties as Multilevel Predictors of Expertise Exchange in Transactive Memory Work Groups. Communication Research, 37(1), 20-47. 
TABLE 1

QUOTES DESCRIBING KNOWLEDGE BOUNDARIES AND TMS IN THE DUTCH HEALTHCARE RESEARCH INSTITUTE

\begin{tabular}{|c|c|}
\hline & $\begin{array}{l}\text { People who come to us with a question about radiation appear to have } \\
\text { little in common with people dealing with Q-fever. What do those two } \\
\text { have in common? Apparently nothing. [...] They speak two different } \\
\text { languages. People should wonder, "What can I learn from someone } \\
\text { else?" "How do these parallels relate?" (RW) }\end{array}$ \\
\hline & $\begin{array}{l}\text { A lot of people talk with each other on a different level. [...] There are so } \\
\text { many subjects, that each has their own dynamics so to speak. [...] I } \\
\text { always say we have colleagues ranging from psychologists to medical } \\
\text { specialists and everything in between them, like sociologists, } \\
\text { epidemiologists, "process people" (people who are working on } \\
\text { processes) and people who are working on content. Knowledge about } \\
\text { processes is a completely different language than knowledge on content. } \\
\text { So how do you connect these two? There are a lot of different axes on } \\
\text { which things can go wrong in communication, not from unwillingness, } \\
\text { but because they don't understand each other. And from thinking they } \\
\text { understand each other, while I can clearly see that they don't. (LS) }\end{array}$ \\
\hline \multirow[t]{2}{*}{$\begin{array}{l}\text { Pragmatic } \\
\text { boundary }\end{array}$} & $\begin{array}{l}\text { Making people make the connections themselves always helps. The } \\
\text { natural habitats of the "nerd" (that is not meant to sound negative, it is } \\
\text { just an abbreviation for people who are very knowledgeable and } \\
\text { experienced in one specific small area of expertise on which they know a } \\
\text { lot), implies a tendency to stick to their own specific subject and go into } \\
\text { depth on that one specific subject. While every now and then it is very } \\
\text { good to do something more into the breadth of a subject, or get } \\
\text { something from outside into their own field. This tendency is not } \\
\text { naturally present with the "nerd". There are often dividing walls in a } \\
\text { knowledge organization that should not be there all the time. These } \\
\text { dividing walls are surrounding people. When you walk through this } \\
\text { building and you walk through the middle, there are all these little goats } \\
\text { standing there in their own sheds, divided by walls. I always think "those } \\
\text { are our nerds". It is very understandable that all of our goats are within } \\
\text { their own little sheds, but every now and then, they do need to look } \\
\text { around the corner. (LS) }\end{array}$ \\
\hline & $\begin{array}{l}\text { Within the different centres, there are definitely differing insights. When } \\
\text { I first came here, I was wondering what they were all up to. It takes a } \\
\text { while before you know. I do think we can be a little bit more open to } \\
\text { each other's point of view. From which point of view do you solve } \\
\text { problems? (BH) }\end{array}$ \\
\hline \multirow[t]{2}{*}{$\begin{array}{l}\text { The } \\
\text { importance } \\
\text { of TMS }\end{array}$} & $\begin{array}{l}\text { It has its pros and cons that you need to go to other people in order to } \\
\text { fulfil your job. I think the situations in which we know all the answers } \\
\text { ourselves are unthinkable. That is just not possible, our field is simply } \\
\text { too big for that. We always need to work with other people. (ES) }\end{array}$ \\
\hline & $\begin{array}{l}\text { Me, I am always very lazy. So what I do when I have a problem that } \\
\text { needs to be dealt with, I lay down in my chair and wonder "who do I } \\
\text { need to have a coffee with". I don't need to think about that as often as } \\
\text { before, but it is the way our memory is organized in a way.(LS) }\end{array}$ \\
\hline
\end{tabular}




\begin{tabular}{|c|c|}
\hline $\begin{array}{l}\text { Inter- } \\
\text { relatedness } \\
\text { between } \\
\text { knowledge } \\
\text { boundaries }\end{array}$ & $\begin{array}{l}\text { The following quote illustrates interconnectedness of knowledge } \\
\text { boundaries that starts from different goals and through developing shared } \\
\text { understanding helps individuals to arrive at common terminology: } \\
\text { Within our organization we work with so many different knowledge } \\
\text { areas and differing backgrounds of people, that we sometimes } \\
\text { don't understand each other. Then you need to take more time to } \\
\text { explain things to others, from their own frame of reference. For } \\
\text { example, we have a centre that works on healthy living, and the } \\
\text { people there are aimed at supporting professionals in the field. We } \\
\text { also have people who work on future public health concerns; those } \\
\text { are people who make a report about the health of Dutch citizens. } \\
\text { That is much more academic. In those two worlds they both use the } \\
\text { term "effectiveness", but it means different things. I discovered } \\
\text { that at a certain moment. And then, people have to talk to each } \\
\text { other, understand that they are talking about two different things } \\
\text { and then discuss that. That can be quite difficult because they have } \\
\text { to step aside from their thoughts and the way they look at things. } \\
\text { That is also a sort of negotiation process, I would say. Eventually } \\
\text { it is about dialectically coming towards a certain knowledge } \\
\text { synthesis in which you speak the same language. But that does } \\
\text { mean that in reports from both parties, things need to be explained } \\
\text { a little more thoroughly. And that takes time. Also to show } \\
\text { externally that within this one organization, we deal with one } \\
\text { perception on "effectiveness". (LS) }\end{array}$ \\
\hline
\end{tabular}


TABLE 2

CONFIRMATORY FACTOR ANALYSIS FOR TMS AS A SECOND ORDER CONSTRUCT

Std. factor

Latent variable (indicators) loading CR AVE

Specialization $0.800 \quad 0.575$

Each team member has specialized knowledge of some aspect of 0.736 our project

The specialized knowledge of several different team members is 0.641 needed to complete the project

I know which team members have expertise in specific areas $\quad 0.880$

Credibility 0.8970 .686

I am comfortable accepting procedural suggestions from other team 0.748 members

I trust that other members' knowledge about the project is credible 0.897

I am confident relying on the information that other team members 0.870 brought to the discussion

I have much faith in other members' expertise

0.790

Coordination

0.892

Our team works together in a well-coordinated fashion

Our team has very few misunderstandings about what needs to be 0.872 done

We work together in a well coordinated and efficient way

There is little confusion about how we need to accomplish the task 0.852 
TABLE 3

CORRELATIONS AND SQUARE ROOTS OF AVE VALUES FOR SPECIALIZATION, CREDIBILITY AND COORDINATION

\begin{tabular}{llll}
\hline & $(1)$ & $(2)$ & $(3)$ \\
\hline Specialization & $\mathbf{0 . 7 5}$ & & \\
Credibility & 0.44 & $\mathbf{0 . 8 3}$ & \\
Coordination & 0.20 & 0.50 & $\mathbf{0 . 8 6}$ \\
\hline
\end{tabular}

Values on diagonal are square roots of AVEs 
CONFIRMATORY FACTOR ANALYSIS FOR TMS AND KNOWLEDGE BOUNDARIES

Std. factor

Latent variable (indicators) loading CR AVE

TMS

0.525

Specialization $0.783 \quad 0.555$

Credibility

0.837

Coordination

0.832

Syntactic boundary (strongly disagree - strongly agree)

When I communicate with my team members, I often find it

0.901

difficult to get relevant information from them because of the

different terminology we use

When I communicate with my team members, I often have

0.904

problems understanding what is relevant and what is not

When I read documents created by my team members, I often

0.750

find it difficult to understand them because they use a different jargon

Semantic boundary

$0.890 \quad 0.670$

My team members and I have a different understanding of our

0.858

project goals

My team members and I have different interpretations of the $\quad 0.879$ meaning of things

Sometimes I initially think I understand my team members, but

0.794

afterwards this turns out not to be correct

I have a different perception of a solution to a problem than my

0.737

team members

Pragmatic boundary

$0.890 \quad 0.729$

It is hard to come to a joint solution with my project team

0.870

If somebody presents a possible solution that requires some team members to change their views, these people find it difficult

When we don't come to an agreement, my team members are generally not willing to change their position 
TABLE 5

CORRELATIONS AND SQUARE ROOTS OF AVE VALUES FOR TMS AND KNOWLEDGE BOUNDARIES

$\begin{array}{llll}(1) & (2) & (3) & (4) \\ \mathbf{0 . 7 5} & & & \\ -0.46 & \mathbf{0 . 8 6} & & \\ -0.43 & 0.62 & \mathbf{0 . 8 2} & \\ -0.58 & 0.42 & 0.46 & \mathbf{0 . 8 5}\end{array}$

Values on diagonal are square roots of AVEs 
FIGURE 1. THEORETICAL MODEL

ragmatic knowledge agmatic knowledge undary
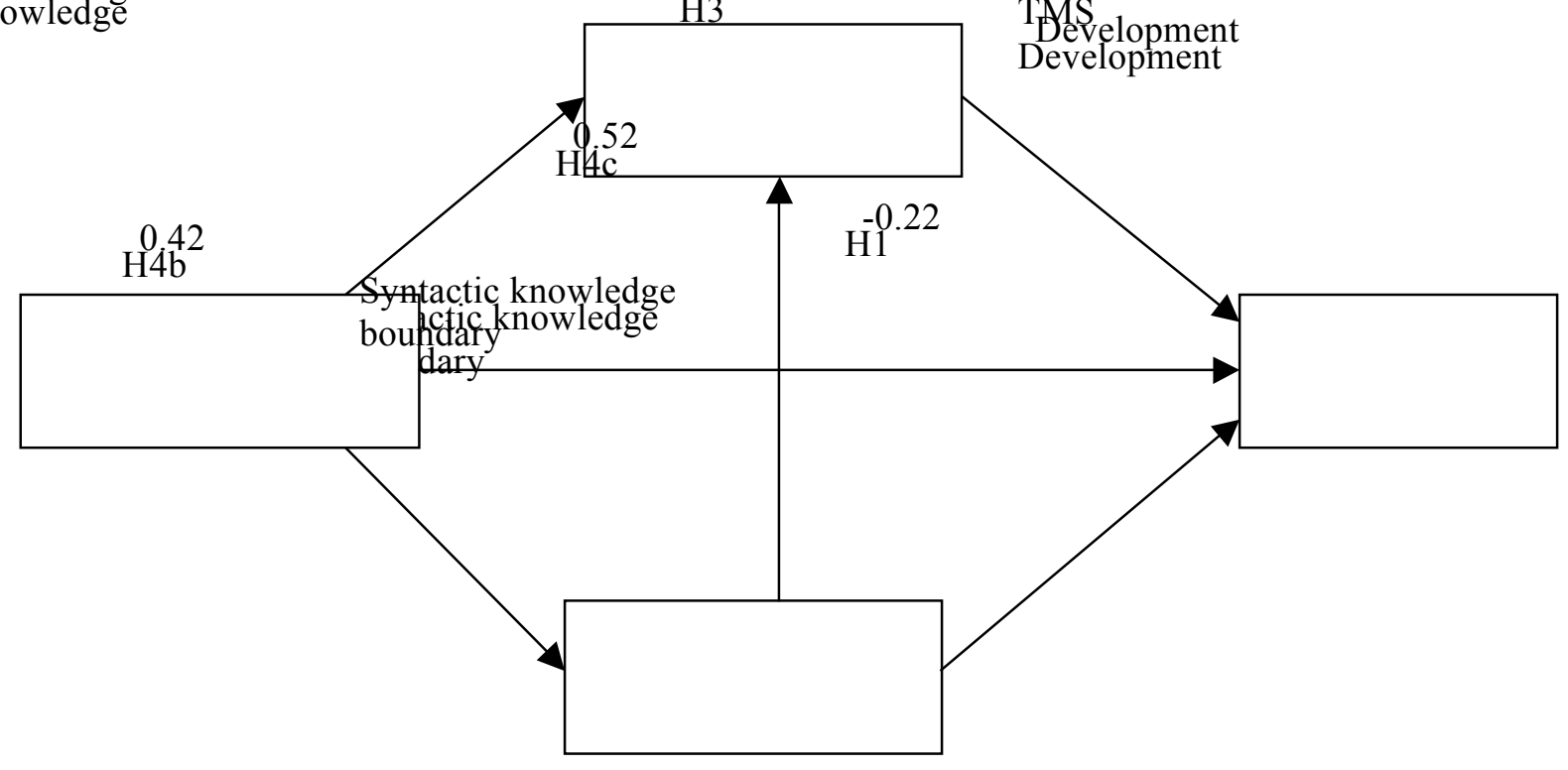

FIGURE 2. TESTED MODEL

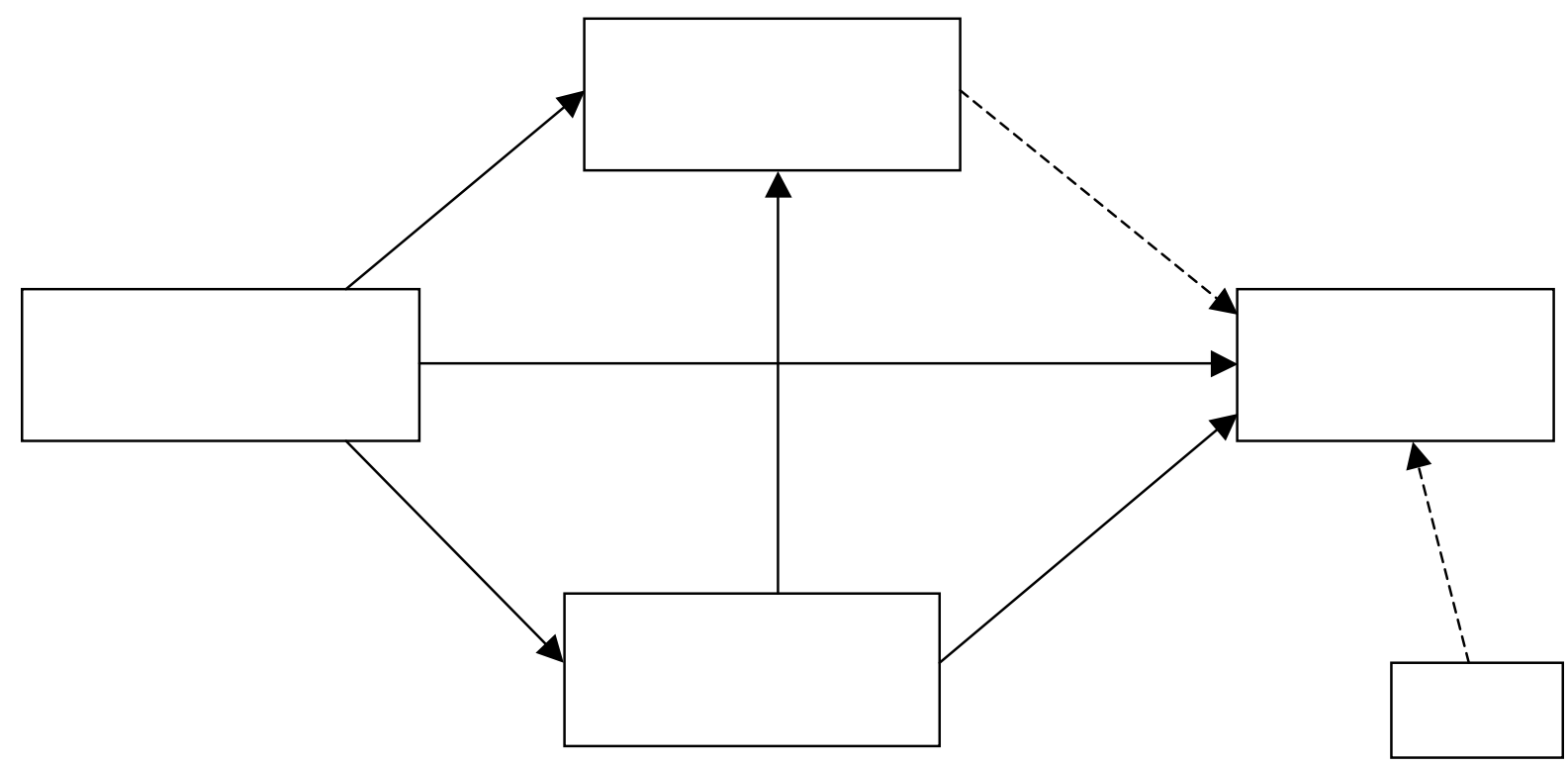




\section{APPENDIX A}

INTERVIEWEE DETAILS

\begin{tabular}{|l|l|l|}
\hline Name (abbreviation)+ & Sex & Role+ \\
\hline HT & Female & Deputy Head of Center A \\
\hline LS & Male & Consultant (across several centers) \\
\hline ES & Male & Team leader of research Center B \\
\hline BH & Female & Deputy head of Center C \\
\hline RW & Male & Director of healthcare research \\
\hline JM & Male & Head of corporate affairs of HRI \\
\hline
\end{tabular}

Note: + Name and Role are anonymous for confidentiality reasons

\section{NOTES}

\footnotetext{
${ }^{1}$ Here we adopt the definition of cross-functional teams from Majchrzak et al. (2012) who use the term "cross-functional" to refer to "the different perspectives that team members bring with them. It represents the individual's specialized knowledge from his or her past or current intrapersonal experience or tenure diversity. This specialized knowledge represents the degree of variety and separation, and not discrepancy, in the team (Harrison \& Klein, 2007). It does not refer to their demographic diversity (e.g., gender, race)" (p. 16).

${ }^{2}$ We would like to thank an anonymous reviewer for this very valuable suggestion.
} 